\title{
Antimicrobial susceptibility patterns of $E$. coli from clinical sources in northeast Ethiopia
}

\author{
*Kibret $\mathrm{M}^{1}$, Abera $\mathrm{B}^{2}$
}

1. Department of Biology, Science College, Bahir Dar University, Bahir Dar, Ethiopia

2. Department of Microbiology, Parasitology and Immunology, College of Medicine and Health Sciences, Bahir Dar University, Bahir Dar, Ethiopia

\begin{abstract}
Background: Escherichia coli is the leading cause of urinary tract, ear, wound and other infections in humans. Increasing rates of antimicrobial resistance among $E$. coli is a growing concern worldwide.

Objectives: The aim of this study was to determine the prevalence and antimicrobial susceptibility of E. coli from clinical samples.

Method: A retrospective review of culture results of urine, ear discharge, pus swab from wounds, and eye discharge was done. A total of 3,149 samples were analyzed for isolation and identification of bacteria and antimicrobial susceptibility testing.

Results: E. coli was isolated from 446 (14.2\%) samples. The highest isolation rate was obtained from urine samples 203 (45.5\%). High resistance rates to erythromycin (89.4\%), amoxicillin (86.0\%) and tetracycline $(72.6 \%)$ were documented. However, significantly high degree of sensitivity rates to nitrofurantoin (96.4\%), norflaxocin (90.6\%), gentamicin (79.6\%) and ciprofloxacin were recorded $(\mathrm{p}<0.001)$. Multiple antimicrobial resistances of $74.6 \%$ and increased resistance rates to all antimicrobials except ciprofloxacin were also recorded.

Conclusion: E. coli isolates showed high rates of resistance to erythromycin, amoxicillin and tetracycline. Nitrofurantoin, norflaxocin, gentamicin and ciprofloxacin are considered appropriate for empirical treatment of E. coli in the study area. Regular monitoring of antimicrobial susceptibility is recommended.
\end{abstract}

Key words: E. coli, antimicrobial susceptibility, Ethiopia

African Health Sciences 2011; 11(S1): S40 - S45

\section{Introduction}

Escherichia coli is a common inhabitant of the human and animal gut, but can also be found in water, soil and vegetation. It is the leading pathogen causing urinary tract infections ${ }^{1,2,3}$ and is among the most common pathogens causing blood stream infections ${ }^{4}$, wounds, otitis media and other complications in humans ${ }^{5,6}$. E. coli is also the most common cause of food and water-borne human diarrhea worldwide and in developing countries, causing many deaths in children under the age of five years ${ }^{7}$.

\section{* Correspondence author \\ Mulugeta Kibret \\ Associate Professor of Microbiology \\ Department of Biology, Science College \\ Bahir Dar University \\ P. O. Box 79 \\ Bahir Dar, Ethiopia \\ Fax: 251-582-205932}

Mobile: 251-918-780300 /251-922-267061

E-mail: mulugetanig@gmail.com
Antimicrobial resistance in E. coli has been reported worldwide and increasing rates of resistance among E. coli is a growing concern in both developed and developing countries ${ }^{8,9}$. A rise in bacterial resistance to antibiotics complicates treatment of infections. In general, up to $95 \%$ of cases with severe symptoms are treated without bacteriological investigation ${ }^{10}$. Occurrence and susceptibility profiles of E. coli show substantial geographic variations as well as significant differences in various populations and environments ${ }^{11}$. In Ethiopia, a number of studies have been done on the prevalence and antimicrobial resistance patterns of E. coli from various clinical sources ${ }^{5,12,13}$. The aim of this study was to determine antimicrobial susceptibility of E. coli from clinical sources at Dessie Regional Health Research Laboratory.

\section{Methods}

\section{Study design}

A retrospective review was done on results of cultures of urine, ear discharge, pus swab from wounds, and eye discharge that had been performed 
from 2003 - 2010 at Dessie Regional Health Research Laboratory. The sex and age of patients. As well as E. coli isolates and antimicrobial susceptibility data were collected from the registration records using a standard data collection form.

\section{Culture and identification}

The specimens were collected from public and private hospitals and health centers. As the standard operation procedures show, clean-catch midstream morning urine specimens are collected using sterile wide mouth glass containers. Urine samples were plated on Cystine Lactose Electrolyte-Deficient medium (CLED), MacConkey agar and, Blood agar (Oxoid, Basingstoke, UK) using calibrated wire loops and then incubated aerobic atmosphere at $37^{\circ} \mathrm{C}$ for 24 hours. From positive cultures, uropathogens were identified according to the standard operational procedures as per the standard microbiological methods ${ }^{14}$. A significant bacterium was considered if urine culture yield $\leq 10^{5}$ colonyforming unit $(\mathrm{CFU} / \mathrm{ml}$.

Samples from discharging ears, eye swab, and pus from wound were collected using sterile cotton swabs ${ }^{14}$. Specimens were inoculated onto $5 \%$ Sheep's blood agar, chocolate agar, mannitol salt agar and MacConkey agar plates (Oxoid Ltd, Basing stoke Hampshire, UK). The plates were incubated at $37^{\circ} \mathrm{C}$ aerobically and examined after 24 and 48 hours.

\section{Antimicrobial susceptibility tests}

According to the standard operational procedures, antimicrobial susceptibility tests were done on Mueller-Hinton agar (Oxoid, Hampshire, England) using Kirby Bauer disk diffusion method ${ }^{15}$. The antimicrobial agents tested were: tetracycline $(30 \mu \mathrm{g})$, nitrofurantoin $(300 \mu \mathrm{g})$, erythromycin $(15 \mu \mathrm{g})$, chloramphenicol $(30 \mu \mathrm{g})$, gentamicin $(10 \mu \mathrm{g})$, ciprofloxacin $(5 \mu \mathrm{g})$, cephalotin $(30 \mu \mathrm{g})$, cotrimoxazole $(25 \mu \mathrm{g})$, ceftriaxone $(30 \mu \mathrm{g})$, norflaxocin and amoxicillin $(10 \mu \mathrm{g})$ (Oxoid, England). Resistance data were interpreted according to National Committee for Clinical laboratory Standards (NCCLS ${ }^{16}$. Reference strains of E. coli ATCC 25922 and $S$. aureus ATCC 25923 were used for quality control for antimicrobial susceptibility tests $^{16}$.

\section{Statistical analysis}

The chi-square test was employed to compare the proportion of bacterial isolates with patient sex and age; and comparison of antimicrobial resistances. P- value of $<0.05$ was considered to indicate statistically significant differences.

\section{Ethical consideration}

Ethical approval was secured from Research Ethics Committee of Bahir Dar University. Permission from Dessie Regional Health Research Laboratory was also obtained.

\section{Results}

Between 2003 and 2010, a total of 3149 samples were analyzed for isolation and identification of bacteria and antimicrobial susceptibility testing. E. coli was isolated from $446(14.2 \%)$ samples. Of these positive cases, the isolation rate of E. coli was the highest in urine samples 203 (45.5\%), followed by $146(32.7 \%)$ in ear discharge, $82(18.7 \%)$ in wound swabs and $15(3.3 \%)$ in eye discharge (Table 1$)$.

Table 1: Distribution of $E$. coli from clinical sources at Dessie regional laboratory (2003 2010)

\begin{tabular}{lclr}
\hline Sample & $\begin{array}{c}\text { Number } \\
\text { of samples } \\
\text { tested }\end{array}$ & $\begin{array}{c}\text { Number } \\
\text { positive for } \\
\text { E. coli }\end{array}$ & $\begin{array}{c}\text { of positive } \\
\text { cases }\end{array}$ \\
\hline Urine & 1404 & $203 / 446$ & 45.5 \\
Ear discharge & 982 & $146 / 446$ & 32.7 \\
Wound swabs & 677 & $82 / 446$ & 18.7 \\
Eye discharge & 86 & $15 / 446$ & 3.4 \\
Total & 3149 & $446 / 3149$ & 14.2 \\
\hline
\end{tabular}

The overall susceptibility patterns of E. coli isolates from various clinical sources is displayed in Table 2. Significantly high resistance rates to erythromycin (89.4\%), amoxicillin (86.0\%) and tetracycline $(72.6 \%)$ were documented $(p=0.001)$. On the other hand, significantly high degree of sensitivity rates to nitrofurantoin (96.4\%), norfloxacin (90.6\%), gentamicin $(79.6 \%)$ and ciprofloxacin were detected $(\mathrm{p}=0.001)$. 
Table 2: Overall antimicrobial susceptibility patterns of $E$. coli isolated from clinical sources at Dessie regional laboratory (2003 - 2010)

\begin{tabular}{lllll}
\hline Antimicrobials & $\begin{array}{l}\text { Total number of } \\
\text { isolates tested }\end{array}$ & $\begin{array}{l}\text { Resistant } \\
\mathrm{N}(\%)\end{array}$ & $\begin{array}{l}\text { Intermediate } \\
\mathrm{N}(\%)\end{array}$ & $\begin{array}{c}\text { Sensitive } \\
\mathrm{N}(\%)\end{array}$ \\
\hline Tetracycline & 351 & $254(72.4)$ & $14(40)$ & $83(23.6)$ \\
Cotrimoxazole & 342 & $215(62.9)$ & $8(2.3)$ & $119(34.8)$ \\
Chloramphenicol & 340 & $120(35.3)$ & $5(1.5)$ & $215(63.2)$ \\
Erythromycin & 199 & $178(89.4)$ & $6(3.0)$ & $15(7.5)$ \\
Amoxicillin & 121 & $104(86.0)$ & $0(0.0)$ & $17(14)$ \\
Cephalotine & 148 & $88(59.5)$ & $6(4.1)$ & $54(36.5)$ \\
Ceftriaxone & 123 & $46(37.4)$ & $1(0.8)$ & $76(61.8)$ \\
Gentamicin & 410 & $71(13)$ & $7(1.7)$ & $332(81.0)$ \\
Ciprofloxacin & 186 & $47(19.9)$ & 0 & $139(74.7)$ \\
Norfloxacin & 31 & $2(6.5)$ & 0 & $29(93.5)$ \\
Nitrofurantoin & 83 & $3(3.6)$ & 0 & $80(96.4)$ \\
\hline p- value & $<0.001$ & & \\
\hline
\end{tabular}

As shown in table 3 , the overall rate of multiple drug resistance was $74.6 \%$ and only $38(8.5 \%)$ of the isolates were sensitive to eight antimicrobials tested. Site specific multiple antimicrobial resistance rates were $100 \%, 76.8 \%, 75.7 \%$ and $67.8 \%$ for eye discharge, urine, wound swab and ear discharge samples respectively.

Table 3: Multiple antimicrobial resistance patterns of $E$. coli isolates from clinical sources at Dessie regional laboratory $(2003-2010)$

\begin{tabular}{llllllllll}
\hline \multicolumn{1}{c}{ Antibiogram $(\mathrm{No}(\%)$} \\
\hline Source /Sample & $\mathrm{R} 0$ & $\mathrm{R} 1$ & $\mathrm{R} 2$ & $\mathrm{R} 3$ & $\mathrm{R} 4$ & $\mathrm{R} 5$ & $\mathrm{R} 6$ & $\mathrm{R} 7$ & $\mathrm{R} 8$ \\
\hline Urine $(\mathrm{n}=203)$ & $15(7.4)$ & $32(15.8)$ & $53(16.2)$ & $45(22.2)$ & $43(21.1)$ & $11(5.4)$ & $3(1.5)$ & - & $1(0.5)$ \\
Ear $(\mathrm{n}=146)$ & $17(9.6)$ & $30(21.9)$ & $38(25.3)$ & $27(17.1)$ & $18(14.4)$ & $9(5.5)$ & $6(5.5)$ & $1(0.7)$ \\
Wound (n=82) & $9(11.0)$ & $11(13.4)$ & $17(20.7)$ & $23(28.0)$ & $14(17.1)$ & $6(7.3)$ & $1(1.2)$ & $1(1.2)$ \\
Eye $(\mathrm{n}=15)$ & - & - & $1(13.3)$ & $7(40.0)$ & $4(26.7)$ & $2(13.3)$ & $1(6.7)$ & - & \\
\hline Total =446 & $38(8.5)$ & $75(16.8)$ & $109(24.4)$ & $99(22.2)$ & $82(18.4)$ & $27(6.1)$ & $13(2.9)$ & $2(0.4)$ & $1(0.2)$ \\
\hline
\end{tabular}

$\mathrm{R} 0=$ Sensitive to all tested antimicrobials; R1, R2, R3, R4, R5, R6, R8 -Resistant to one, two, three, four, five, six, eight antimicrobials, respectively.

The chi-square test for trend shown in table 4 demonstrates increased resistance rates to seven antimicrobials. In 2003, E. coli resistance to tetracycline were $68.4 \%$, to gentamicin $14.3 \%$, chloramphenicol $50.0 \%$, cotrimoxazole $67.2 \%$, cephalotin $56.9 \%$, amoxicillin $76.9 \%$ and erythromycin $75.2 \%$.
However, in 2010 the resistance rates were tetracycline $76.3 \%$, gentamicin $13.9 \%$, chloramphenicol $58.1 \%$, cotrimoxazole $68.4 \%$, cephalotin $91.7 \%$, amoxicillin $(93.3 \%)$ and erythromycin $94.6 \%$, with an increase in rates of 1.2 $-34.8 \%$.

Table 4: Chi square test for trend applied to $E$. coli resistance rates to various antimicrobials for eight years at Dessie regional laboratory (2003 - 2010)

\begin{tabular}{|c|c|c|c|c|c|c|c|c|c|c|}
\hline \multirow[b]{2}{*}{ Antimicrobials } & \multicolumn{2}{|c|}{2003} & \multicolumn{2}{|l|}{2004} & \multicolumn{2}{|l|}{2005} & \multicolumn{2}{|c|}{2006} & \multirow[t]{2}{*}{$\mathrm{X}^{2}$ for trend } & \multirow[t]{2}{*}{$\mathrm{p}$-value } \\
\hline & $\#^{\mathrm{a}}$ & $\% \mathrm{R}^{\mathrm{b}}$ & \#T $^{\mathrm{a}}$ & $\% \mathrm{R}^{\mathrm{b}}$ & $\# \mathrm{~T}^{\mathrm{a}}$ & $\% \mathrm{R}^{\mathrm{b}}$ & \#T $^{\mathrm{a}}$ & $\% \mathrm{R}^{\mathrm{b}}$ & & \\
\hline Tetracycline & 57 & 68.4 & 49 & 71.4 & 22 & 77.3 & 24 & 87.5 & 43.02 & $<0.001$ \\
\hline Gentamicin & 63 & 14.3 & 61 & 23.0 & 55 & 30.9 & 33 & 30.3 & 47.16 & $<0.001$ \\
\hline Chloramphenicc & ol 52 & 50.0 & 50 & 40.0 & 34 & 44.1 & 15 & 40.0 & 60.7 & $<0.001$ \\
\hline Cotrimoxazole & 61 & 67.2 & 55 & 58.2 & 24 & 58.3 & 21 & 76.2 & 26.94 & 0.003 \\
\hline Cephalotine & 51 & 56.9 & 32 & 53.1 & 1 & 100.0 & 3 & 100.0 & 301.6 & $<0.001$ \\
\hline Amoxicillin & 13 & 76.9 & 32 & 84.4 & 20 & 90.0 & 17 & 76.5 & 260.3 & $<0.001$ \\
\hline Ciprofloxacin & 11 & 36.4 & - & & & & & & 77.86 & \\
\hline Erythromycin & 4 & 75.0 & 4 & 50.0 & 18 & 88.9 & 17 & 88.2 & 68.8 & $<0.001$ \\
\hline
\end{tabular}


Continuation of table 4

\begin{tabular}{|c|c|c|c|c|c|c|c|c|c|c|}
\hline & 2007 & & 2008 & & 2009 & & 2010 & & $\mathrm{X}^{2}$ for trend & p-value \\
\hline Antimicrobials & $\# \mathrm{~T}^{\mathrm{a}}$ & $\% \mathrm{R}^{\mathrm{b}}$ & $\# \mathrm{~T}^{\mathrm{a}}$ & $\% \mathrm{R}^{\mathrm{b}}$ & $\# \mathrm{~T}^{\mathrm{a}}$ & $\% \mathrm{R}^{\mathrm{b}}$ & $\# \mathrm{~T}^{\mathrm{a}}$ & $\% \mathrm{R}^{\mathrm{b}}$ & & \\
\hline Tetracycline & 70 & 81.4 & 34 & 93.82 & 35 & 85.7 & 38 & 76.3 & 43.02 & $<0.001$ \\
\hline Gentamicin & 75 & 4.0 & 56 & 7.8 & 37 & 21.6 & 36 & 13.9 & 47.16 & $<0.001$ \\
\hline Chloramphenicc & 71 & 16.9 & 50 & 33 & 31 & 21.6 & 37 & 58.1 & 60.7 & $<0.001$ \\
\hline Cotrimoxazole & 63 & 71.4 & 49 & 49.34 & 28 & 67.9 & 38 & 68.4 & 26.94 & 0.003 \\
\hline Cephalotine & 23 & 56.5 & 7 & 31.4 & 8 & 12.5 & 24 & 91.7 & 301.6 & $<0.001$ \\
\hline Amoxicillin & 7 & 100.0 & 2 & 55 & 2 & 50.0 & 30 & 93.3 & 260.3 & $<0.001$ \\
\hline Ciprofloxacin & 358.6 & 43 & 32.6 & 36 & 11.1 & 11 & 17.1 & 77.86 & & \\
\hline Erythromycin & 41 & 87.8 & 45 & 92.9 & 32 & 100.0 & 37 & 94.6 & 68.8 & $<0.001$ \\
\hline
\end{tabular}

$\mathrm{a}=$ number of isolates tested against each antimicrobial agent

$\mathrm{b}=$ Percent of isolates resistant to the antimicrobial agent

\section{Discussion}

Antimicrobial resistance in E. coli has increased worldwide and its susceptibility patterns show substantial geographic variation as well as differences in population and environment ${ }^{17}$. The isolation rate of E. coli in the present study was $14.2 \%$ and it was commonly isolated from urine samples $(45.5 \%)$. These findings are in conformity with reports by other researchers ${ }^{13,18,19}$.

In this study, the overall resistance of E. coli to antimicrobials was high. The result is consistent with the findings of previous studies ${ }^{20}$. The resistance rates recorded in this study are higher than the results of Khan et al. ${ }^{6}$ and lower than the results of Iqbal and Patel ${ }^{21}$ and Okonko et al. ${ }^{22}$. High level of resistance in E. coli was reported to tetracycline from a study conducted in Ethiopia ${ }^{23}$ and to erythromycin from a study done in Sloveni ${ }^{24}$.

In all clinical samples, E. coli showed high resistance rates of $>80 \%$ to erythromycin and amoxicillin and $>60 \%$ to tetracycline. The results of this study are in line with the findings of other studies conducted in different parts of the world ${ }^{25}$, ${ }^{26}$. However, the antimicrobial resistance rates obtained in this study were higher compared to susceptibility patterns reported from previous studies $^{27,28,29}$.

E. coli isolates were sensitive to gentamicin, nitrofurantoin, ciprofloxacin and chloramphenicol. Similar studies conducted in Ethiopia ${ }^{30}$ and Nigeria ${ }^{31}$ have reported comparable susceptibility rates. High sensitivity to ciprofloxacin and gentamicin and norfloxacin have been recorded from previous studies conducted in Nigeria and India ${ }^{31,32}$. In this study, norfloxacin, ciprofloxacin, gentamicin and chloramphenicol were found to be the most effective antimicrobials against E. coli isolates.
Furthermore $\mathrm{n}$ this study, a high rate of multiple antimicrobial resistance was recorded, which is consistent with the reports of studies done elsewhere ${ }^{21,33}$. The chi-square test for trend demonstrated increased resistance rates to all antimicrobials except ciprofloxacin. Increases in rates of resistance to different antimicrobials have been reported from previous studies conducted in different parts of the world $20,33,34$.

\section{Conclusion}

The results of this study show high rates of antimicrobial resistance to erythromycin, amoxicillin and tetracycline. Nitrofurantoin, norfloxacin gentamicin and ciprofloxacin are considered appropriate for empirical treatment of E. coli in the study area. Periodic monitoring of antimicrobial susceptibility both in the community and hospital settings is recommended.

\section{Acknowledgments}

We thank Mr Fekadu Birru, Head of Dessie Retinal Health Research Laboratory for supporting this research. We also thank all staff of Microbiology department of Dessie Regional Health Research Laboratory for their proper documentation.

\section{References}

1. Wagenlehner FM, Naber KG, Weidner W. Rational antibiotic therapy of urinary tract infections. Med Monatsschr Pharm. 2008; 31: 385-90.

2. De Francesco MA, Giuseppe R, Laura P, Riccardo, N, Nin M. Urinary tract infections in Brescia, Italy: Etiology of uropathogens and 
antimicrobial resistance of common Uropathogens Med Sci Moni. 2007; 13(6): 136-144.

3. Kashef N, Djavid GE, Shahbazi S. Antimicrobial susceptibility patterns of community-acquired uropathogens in Tehran, Iran. J Infect Dev Ctries. 2010; 4(4): 202-206.

4. Biedenbach DJ, Moet GJ, Jones RN. Occurrence and antimicrobial resistance pattern comparisons among bloodstream infection isolates from the SENTRY Antimicrobial Surveillance Program (1997-2002). Diagn Microbiol Infect Dis. 2004; 50: 59-69.

5. Gebre-Sellassie S.. Antimicrobial resistance patterns of clinical bacterial isolates in southern Ethiopia. Ethiop Med J. 2007; 45(4): 363-370.

6. Khan NA, Saba N, Abdus S, Ali AQ. Incidence and antibiogram patterns of E. coli isolates from various clinical samples from patients at NIH Islamabad. Pak J Biol Sci. 2002; (1):111-113.

7. Turner SM, Scott-Tucker A, Cooper LM, Henderson IR. Weapons of mass destruction: virulence factors of the global killer enterotoxigenic Escherichia coli. FEMS Microbial Letters. 2006; 263(1): 10-20.

8. Bell JM, Turnidge JD, Gales AC, Pfaller M. Jones RN, Sentry APAC Study Group. Prevalence of extended spectrum beta-lactamase (ESBL)producing clinical isolates in the Asia-Pacific region and South Africa: regional results from SENTRY Antimicrobial Surveillance Program (1998-99). Diagn Microbiol Infect Dis. 2002; 42: 193-198.

9. El Kholy A, Baseem H, Hall G, Procop GW, Longworth DL. Antimicrobial resistance in Cairo, Egypt 1999-2000: a survey of five hospitals. J Antimicrob Chemother. 2003; 51: 625630.

10. Dromigny JA, Nabeth P, Juergens-Behr A, Perrier-Gros-Claude JD. Risk factors for antibiotic resistant Escherichia coli isolated from community-acquired urinary tract infections in Dakar, Senegal. J Antimicrobial Chemother. 2005; 56: 236-239.

11. Erb A, Stürmer T, Marre,R BrennerH. Prevalence of antibiotic resistance in Escherichia coli: overview of geographical, temporal, and methodological variations. Eur J Clin Microbial Infect Dis. 2007; 26: 83-90.
12. Endalafer N, Gebre-Selassei S, Kotisso B. Nosocomial bacterial infections in a tertiary hospital in Ethiopia. J Infect Prev. 2011; 12 (1): 38-43.

13. Yismaw G, Abay S, Asrat D, Yifru S, Kassu A Bacteriological profile and resistant patterns of clinical isolates from pediatric patients, Gondar University Teaching Hospital, Gondar Northwest Ethiopia. Ethiop. Med. J. 2010; 48(4): 293-300.

14. Cheesbourgh M. Medical laboratory manual for tropical countries. $2^{\text {nd }}$ edition: England: Butterworth-Heineman LTD, 1991; 114-6.

15. Bauer, A.W., Kirby, W.M.M., Sherris, J.C. and Turck, M. Antibiotic susceptibility testing by standard single disc method. Am J. Clin Pathol 1996; 45: 493-496.

16. National Committee for Clinical Laboratory Standards. Methods for determining bactericidal activity of antimicrobial agents. Tentative Guidelines, M26-TNCCLS.Villanova, PA. 1993.

17. von Baum H, Reinhard M. Antimicrobial resistance of Escherichia coli and therapeutic implications. Inter J Med Microbiol. 2000; 295: 503511.

18. Al-Tawfiq JA. Increasing antibiotic resistance among isolates of Escherichia coli recovered from inpatients and outpatients in a Saudi Arabian Hospital. Infect Control Hosp Epidemiol 2006; 27: 748-753.

19.Gangoué JP, Koulla-Shirob S, Ngassama P, Adiogo D, Njine T, Ndumbe P. Antimicrobial resistance of Gram-negative bacilli isolates from inpatients and outpatients at Yaounde Central Hospital, Cameroon. Inter J Infect Dis. 2004; 8: 147-154.

20. Orrett FA, Shurl SM. Prevalence of resistance to antimicrobial of $E$. coli isolates from clinical sources at a private hospital in Trinidad. Jpn J Infect Dis. 2001; 54: 64-68.

21. Iqbal MK, Patel IK. Susceptibility patterns of Escherichia coli: Prevalence of multidrug-resistant isolates and extended spectrum beta-Lactamase phenotype. J Pak Med Asso. 2002; 52: 407-417.

22. Okonko IO. Soleye FA, Amusan TA, Ogun AA, Ogunnusi TA Ejembi J. Incidence of multi-drug resistance (MDR) organisms in Abeokuta, Southwestern Nigeria. Global J Pharm. 2009; 3(2): 69-80. 
23. Andargachew M, Feleke M, Tesesma B, Afewerk K. Pattern and multiple drug resistance of bacterial pathogens isolated from wound infection at University of Gondar Teaching Hospital, Northwest Ethiopia. Ethiop Med J. 2006; 44(2): 125-31.

24. Petkovsjek Z, Elersjic; K, Gubina M, ZigurBertok D, Erjavec S. Virulence potential of Escherichia coli isolates from skin and soft tissue infections. J Clin Microbiol. 2009; 47(6): 18111817.

25. Bharathi MJ, Ramakrishnan R, Maneksha V, Shivakuma C, Mittal S. Comparative bacteriology of acute and chronic dacryocystitis. Eye 2008; 22: 953-960.

26. Briscoe D, Rubowitz A, Assia EI. Changing bacterial isolates and antibiotic sensitivities of purulent dacryocystitis. Orbit 2005; 24: 95-98. 24.

27. Zhanel, GG, Hisanaga TL, Laing NM, De Corby MR, Nichol KA, Weshnoweski et al. Antibiotic resistance in Escherichia coli outpatient urinary isolates: final results from the North American Urinary Tract Infection Collaborative Alliance (NAUTICA). Int J Antimicrob Agents. 2006; 27: 468-475.

28. Karlowsky JA, Kelly LJ, Thornsberry C, Jones ME Sahm DF. Trends in antimicrobial resistance among urinary tract infection isolates of Escherichia coli from female outpatients in the United States. Antimicrob Agents Chemother. 2002; 6: 2540-2545.
29. Barrett SP, Savage MA, Rebec MP, Guyot A, Andrews N, Shrimpton SB. Antibiotic sensitivity of bacteria associated with community-acquired urinary tract infection in Britain. J Antimicrob Chemother. 2000; 44: 359-365.

30. Tesfaye G, Asrat D, Woldeamanuel Y, Gizaw M. Microbiology of discharging ears in Ethiopia. Asian Pac J Trop Med 2009; 2(91): 60-67.

31. Wariso BA,Ibe SN. Bacteriology of chronic discharging ears in Port Harcourt, Nigeria. West Afr J Med. 2006; 25: 219-222.

32. Bharathi MJ, Ramakrishnan R, Meenakshi R, Palaniappan R. In-Vitro efficacy of antibacterials against bacterial isolates from corneal ulcers. Indian J Ophthalmol. 2002; 50: 109-114.

33. Kurutepe S, Surucuoglue S, Sezgin C, Gazi H, Gulay M, Ozbakkaloglu B. Increasing antimicrobial resistance in E.coli isolates form community-acquired urinary tract infections during 1998 - 2003 in Minisa, Turkey. Jpn J Infect Dis. 2005; 58: 159-161.

34. Kahlmeter G. An international survey of the antimicrobial susceptibility of pathogens from uncomplicated urinary tract infections: the ECOSENS Project. J Antimicrobl Chemother. 2003; 51: 69-76. 